\title{
Flexabrasion Applied to the Evaluation of the Photodegradation of Hair Fibers
}

\author{
Nathália F. de Oliveira ${ }^{1,2}$, Rima Rakshit ${ }^{3}$, Anthony Galliano ${ }^{4}$, Daiane Garcia Mercurio ${ }^{2}$, \\ Elcio Cruz de Oliveira ${ }^{1,5, *(D)}$ and Elisabeth Costa Monteiro ${ }^{1}$ (D) \\ 1 Postgraduate Programme in Metrology, Pontifical Catholic University of Rio de Janeiro, \\ Rio de Janeiro 22451-900, Brazil; nathalia.oliveira2@rd.loreal.com (N.F.d.O.); beth@puc-rio.br (E.C.M.) \\ 2 L'Oréal Research \& Innovation, Rio de Janeiro 21941-972, Brazil; daiane.mercurio@rd.loreal.com \\ 3 L'Oréal Research \& Innovation, Mumbai 400071, India; rima.rakshit@rd.loreal.com \\ 4 L'Oréal Research \& Innovation, 93400 Saint Ouen, France; anthony.galliano@rd.loreal.com \\ 5 Technology Management, Petrobras Transporte S.A., Rio de Janeiro 20091-060, Brazil \\ * Correspondence: elciooliveira@puc-rio.br
}

check for

updates

Citation: de Oliveira, N.F.; Rakshit, R.; Galliano, A.; Mercurio, D.G.; de Oliveira, E.C.; Monteiro, E.C. Flexabrasion Applied to the Evaluation of the Photodegradation of Hair Fibers. Cosmetics 2022, 9, 1. https://doi.org/10.3390/ cosmetics 9010001

Academic Editors: Remo Campiche, Marta Bertolini and

Emmanuel Martin

Received: 21 November 2021

Accepted: 16 December 2021

Published: 21 December 2021

Publisher's Note: MDPI stays neutral with regard to jurisdictional claims in published maps and institutional affiliations.

Copyright: (c) 2021 by the authors. Licensee MDPI, Basel, Switzerland. This article is an open access article distributed under the terms and conditions of the Creative Commons Attribution (CC BY) license (https:/ / creativecommons.org/licenses/by/ $4.0 /)$.

\begin{abstract}
Solar radiation is a significant source of damage to hair fibers. However, the instrumental measurement of the consequences of its interaction with hair fibers' constituents remains a challenge. In this work, the flexabrasion methodology was investigated as a potential tool to quantify the damage to mechanical hair properties caused by solar rays. The in vitro experiment developed for this study simulated four initial conditions of human hair samples, which subsequently underwent different periods of exposure to the radiation emitted by a Xenon arc lamp source. The statistical analysis of the results characterized the methodology's ability to evaluate the impact of solar radiation on the hair's mechanical resistance. More evident effects were observed on natural fibers subjected to exposures of up to $60 \mathrm{~h}$ and over, corresponding to about $1.5 \mathrm{~h}$ per day of sun exposure in Rio de Janeiro over five months. The results point to flexabrasion as an option to evaluate the photoprotection efficacy offered by hair-care products.
\end{abstract}

Keywords: metrology; hair fiber; solar radiation; photoprotection; Mann-Whitney non-parametric test; flexabrasion; mechanical properties

\section{Introduction}

Markers of the effect of solar radiation on the constituents of hair fibers are not yet well-established in the literature [1]. Thus, the development of products for photoprotection is still a challenge to the cosmetics industry.

Several studies investigate the signs of photodamage in hair strands [1-9]; however, their conclusions often diverge, mainly due to the experimental method design, with differences in samples preparation, regarding aspects that can directly affect the results, such as the source of irradiation, the intensity of exposure, the dose of radiation, and the characteristics of the hair sample, as illustrated in Table 1 for other similar studies [2-5]. In [2], hair swatches were exposed to an ultraviolet lamp for 15 days and tested via a tensile strength method. Their results have shown that exposure induces significant changes in the fiber's elastic modulus and breaking stress. In contrast, another investigation published three years later [3], in 2004, used mercury vapor lamps and indicated no alterations in the same parameters after $448 \mathrm{~h}$ of exposure. Similarly, in a study published in 2011 [4], after UV exposure of hair swatches for $480 \mathrm{~h}$, it has been shown that the 18-methyleicosanoic acid (18-MEA) layer vanished due to irradiation. Being an essential constituent of the hair cuticle, 18-MEA is a fatty acid that bonds to the outermost layer of the shaft, strongly contributing to the hydrophobicity of the fiber's surface [10]. Published in 2015 [5], another study, also investigating 18-MEA upon radiation exposure, subjected hair samples to the energy emitted from a mercury vapor lamp for $600 \mathrm{~h}$. The analysis indicated that the 18-MEA layer was not changed or removed after being irradiated. Thus, contrasting with 
the conclusions drawn by the authors of [4], the research in [5] did not blame solar radiation for degrading this cuticle lipid layer.

Table 1. Some examples of studies whose authors' conclusions vary, depending on the methodology employed to expose the hair fiber to radiation and measure its resulting effect.

\begin{tabular}{|c|c|c|c|}
\hline Reference & Exposure Methodology & Measurement Strategy & Conclusion \\
\hline [2] 2001 & $\begin{array}{c}\text { Hair swatches subjected } \\
\text { to an ultraviolet lamp } \\
\text { for } 360 \mathrm{~h} .\end{array}$ & $\begin{array}{c}\text { Mechanical } \\
\text { (tensile strength test } \\
\text { method) }\end{array}$ & $\begin{array}{l}\text { Elastic modulus and } \\
\text { breaking stress of the } \\
\text { fiber were significantly } \\
\text { changed after exposure. }\end{array}$ \\
\hline [3] 2004 & $\begin{array}{l}\text { Hair swatches exposed } \\
\text { to a mercury vapor lamp } \\
\text { for } 448 \mathrm{~h} .\end{array}$ & $\begin{array}{c}\text { Mechanical } \\
\text { (tensile strength test } \\
\text { method) }\end{array}$ & $\begin{array}{l}\text { There were no } \\
\text { alterations to the hair } \\
\text { fiber's elastic modulus } \\
\text { and breaking stress. }\end{array}$ \\
\hline [4] 2011 & $\begin{array}{l}\text { Hair swatches exposed } \\
\text { to a solar simulator for } \\
\qquad 480 \mathrm{~h} .\end{array}$ & $\begin{array}{l}\text { Chemical } \\
\text { (18-MEA layer } \\
\text { evaluation) }\end{array}$ & $\begin{array}{l}\text { The 18-MEA layer was } \\
\text { removed by irradiation. }\end{array}$ \\
\hline [5] 2015 & $\begin{array}{l}\text { Hair swatches exposed } \\
\text { to a mercury vapor lamp } \\
\text { for } 600 \mathrm{~h} .\end{array}$ & $\begin{array}{l}\text { Chemical } \\
\text { (18-MEA layer } \\
\text { evaluation) }\end{array}$ & $\begin{array}{c}\text { The 18-MEA layer was } \\
\text { not altered or removed } \\
\text { by irradiation. }\end{array}$ \\
\hline
\end{tabular}

The measurement of alterations to the mechanical properties of hair is an approach that is closer to people's sensory perception of damage since lower fiber resistance can easily be perceived on a macro scale and, thus, be correlated to the common experience of brittle hair.

Tensile strength is a standard method to measure the mechanical resistance of different materials, including hair fibers $[2,3,11,12]$. On the other hand, as shown in Table 1 , depending on the assay conditions [2,3], the effect of solar radiation on the tensile properties of hair can be very low or even null. Indeed, these mechanical properties are ruled mainly by the organized proteins of the hair cortex $[6,7,13,14]$. The rigid structure of the hair cortex is provided by fibrous units made up of keratin proteins, iteratively aggregated in a longitudinal direction $[13,14]$. Raman microspectroscopy studies indicate that the photoinduced cleavage of disulfide bonds is associated with conformational changes of keratins in irradiated hair. [15] Thus, to reach and damage the cortex, a deeper region of the hair shaft, the solar radiation must penetrate through the multiple layers of cuticle cells [9]. Consequently, the cuticle's amino acids are more damaged than those from the cortical region, due to the higher intensity of solar radiation that reaches the surface layers $[1,5,8,9,11,16]$. Being primarily associated with cortical properties, when only the cuticle had been damaged, no significant change has been demonstrated to the tensile properties [7]. As a result, the conflicting results shown in Table 1 regarding tensile properties may stem from different levels of cortex damage due to non-harmonized irradiation procedures and not adequately evaluating the cuticle damage. This evidence points to the importance of incorporating approaches suitable for cuticle cell layer analysis in the mechanical evaluation process.

The flex fatigue methodology, described in the literature as an efficient way to measure the mechanical resistance of fibers [17], is widely used in the textile industry [18]. The measurement result of this test method is the number of cycles that precede breakage: the higher the strength of the fiber, the greater the number of cycles. The first mention of flex fatigue usage applied to cosmetics occurred in 1995 [19] when the technique was adapted to hair science and named "flexabrasion" [20]. This approach evaluates the mechanical properties that tensile measurements also provide, including bending stress analysis, which better addresses the outermost layers' integrity. Hence, flexabrasion could better evaluate the mechanical properties associated with the cortex or cuticle damage.

The present work aims to evaluate the potential of the flexabrasion methodology in detecting the impact of solar radiation on the mechanical integrity of hair fibers, by performing a systematic in vitro analysis based on realistic environmental exposure conditions. The development of this method aims to create a harmonized procedure with appropriate sensitivity to the level of exposure to solar beams that is able to contribute to 
the comparability of the results of scientific studies exploring the impact of solar radiation on hair fibers, as well as to support conformity assessment approaches for the efficient evaluation of hair photoprotection products.

\section{Materials and Methods}

This section describes the procedures for hair sample preparation, solar exposure simulation, and a flexabrasion essay to evaluate the mechanical properties of hair fibers. Section 2.1 explains the first step of the procedure, simulating the different initial conditions of the hair samples before they are subjected to the developed protocol of solar exposure, corresponding to the second step explained in Section 2.2. The third step of the procedure is presented in Section 2.3, concerning the flexabrasion measurements of the samples' mechanical properties after being prepared (Section 2.1) and, subsequently, irradiated (Section 2.2).

\subsection{Hair Sample Preparation}

The hair tresses, bought from the supplier International Hair Importers \& Products, Inc (New York, NY, USA), were prepared from randomized and standardized fibers of brown natural human hair, with a curliness degree of type 3, according to de la Mettrie's scale [21], originally from people of Brazilian nationality.

The assembled hair swatches have been divided into the four groups described in Table 2, each taking into account different chemical transformation procedures to achieve different levels of preliminary sensitization.

Table 2. Preparation of hair swatches to simulate the four different sensitization levels, performed before each of these groups was exposed to radiation.

\begin{tabular}{cl}
\hline Group & Protocol of Application of the Chemical Procedure \\
\hline Natural hair (NA) & The swatches of this group were not subjected to any \\
procedure of chemical transformation. & The swatches of this group were subjected to 2 \\
Bleached hair (BL) & applications of bleach using a bleach mixture containing \\
& 12\% hydrogen peroxide, with 45 min of pause time. \\
Dyed hair (DY) & The swatches of this group were subjected to 1 \\
& application of a hair coloring mixture containing $9 \%$ \\
& hydrogen peroxide, with 35 min of pause time. \\
& The swatches of this group were subjected to 1 \\
application of a straightening product containing $8.5 \%$ & formaldehyde. Here, 30 min of pause time was followed \\
by brushing (using a hairdryer) and flat ironing.
\end{tabular}

\subsection{Solar Exposure Simulation}

Damage caused by solar exposure was reproduced using the Ci3000 machine from Atlas Material Testing Technology (Mount Prospect, IL, USA), with a Xenon Arc lamp surrounded by 2 " $\mathrm{S}$ " borosilicate filters, in order to simulate outdoor weathering [22]. The lamp irradiated from 300 to $800 \mathrm{~nm}$, at $40{ }^{\circ} \mathrm{C}$ and $50 \%$ relative humidity. An intensity level of $60 \mathrm{~W} \cdot \mathrm{m}^{-2}$ was defined for the wavelength range of from 300 to $400 \mathrm{~nm}$.

Based on data from the ASTM (the American Society for Testing and Materials) G17303 [23] and data regarding the solar energy per day in Rio de Janeiro in 2015 supplied by Climatempo Assessoria e Consultoria Meteorologica LTDA. (Vila Mariana, São Paulo, Brazil), it has been estimated that one hour of exposure to the Xenon arc lamp in these conditions is equivalent to approximately $4.2 \mathrm{~h}$ of solar exposure in Rio. For the purposes of this experiment, it has been decided to expose the hair to different doses of irradiation, corresponding to $10 \mathrm{~h}, 30 \mathrm{~h}, 60 \mathrm{~h}, 90 \mathrm{~h}, 120 \mathrm{~h}$, and $150 \mathrm{~h}$ of exposure to the Xenon arc lamp. 


\subsection{Flexabrasion Test Method}

The equipment Fiberstress DTM-371 from Textechno (Textechno Herbert Stein GmbH \& Co. KG, Mönchengladbach, Germany) was used to assess the resistance of the hair fibers before and after the exposure. Fifty hair shaft samples were analyzed for each of the four conditions of sensitization (Table 2), using a $10 \mathrm{~mm}$ amplitude range, a frequency of $0.5 \mathrm{~Hz}$, and an abrasion angle of $90^{\circ}$ (Figure 1). The experiment was carried out inside a glove box, under $50 \%$ of relative humidity and a temperature of $24^{\circ} \mathrm{C}$.

In this type of test method, a section under tension of the fiber is bent repeatedly while moving back and forth in contact with a fixed pin, as illustrated in Figure 1.

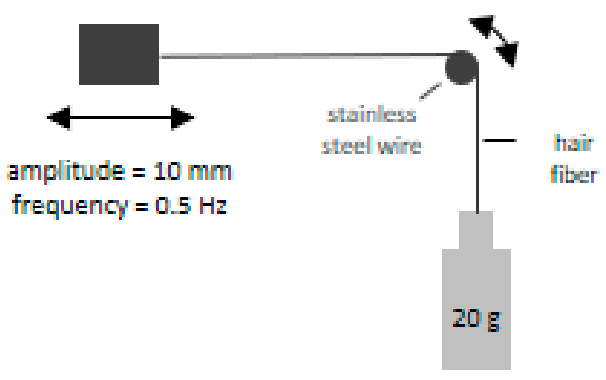

Figure 1. Flexabrasion assembly used for hair fiber mechanical analysis.

The output of this essay is the number of flexabrasion cycles completed before the fiber ruptures. Flexabrasion measurements were performed with the four groups of hair swatches with pretreatment (NA, BL, DY, ST) before being exposed to the Xenon Arc lamp, which corresponds to the time $t=0 \mathrm{~h}$; and after exposure to the radiation doses corresponding to each of the different exposure periods adopted in the procedure ( $10 \mathrm{~h}$, $30 \mathrm{~h}, 60 \mathrm{~h}, 90 \mathrm{~h}, 120 \mathrm{~h}$, and $150 \mathrm{~h}$ ).

In general, the data obtained that arose from this test method did not follow a normal distribution; thus, the Mann-Whitney non-parametric test was applied, considering 5\% of significance level [24]. The outliers have been treated using the interquartile range methodology.

\section{Results and Discussion}

This section presents and discusses the results obtained via the flexabrasion essay in Section 3.1. Section 3.2 estimates the equivalent dose of radiation needed to achieve significant signs of mechanical sensitization, applicable to the harmonized analysis of hair photodamage and the conformity assessment of photoprotection products.

\subsection{Flexabrasion Test Results}

The results of flexabrasion measurements obtained for each hair sample sensitization group we analyzed are presented in Table 3, where the numerical values correspond to the number of cycles needed to break the fibers when subjected to the mechanical demands of the test. In Table 3, the results for natural (NA), bleached (BL), colored (DY), and straightened (ST) hair groups are presented according to the degree of exposure to the Xenon arc lamp. Since the data show non-parametric, the expanded uncertainties were calculated using the same approach used in [25]. 
Table 3. Descriptive statistics of hair samples analyzed via the flexabrasion method, expressed as the number of cycles before shaft breakage.

\begin{tabular}{|c|c|c|c|c|c|c|c|c|}
\hline \multirow{3}{*}{ Exposure Time } & \multicolumn{8}{|c|}{ Number of Cycles before Hair Fiber Breakage } \\
\hline & \multicolumn{4}{|c|}{ Median } & \multicolumn{4}{|c|}{ Expanded Uncertainty } \\
\hline & NA & BL & DY & ST & NA & BL & DY & ST \\
\hline $0 \mathrm{~h}$ & 434.00 & 273.50 & 304.50 & 33.00 & 42.36 & 46.06 & 57.73 & 5.75 \\
\hline $10 \mathrm{~h}$ & 426.50 & 255.50 & 312.50 & 18.50 & 69.45 & 41.34 & 55.89 & 12.19 \\
\hline $30 \mathrm{~h}$ & 397.00 & 247.50 & 280.50 & 22.00 & 66.51 & 56.41 & 95.73 & 7.93 \\
\hline $60 \mathrm{~h}$ & 389.50 & 213.50 & 287.50 & 17.00 & 72.66 & 59.04 & 77.71 & 6.35 \\
\hline $90 \mathrm{~h}$ & 288.50 & 210.50 & 282.50 & 26.50 & 34.63 & 45.60 & 50.58 & 8.65 \\
\hline $120 \mathrm{~h}$ & 338.50 & 240.00 & 254.50 & 34.00 & 53.20 & 76.40 & 70.70 & 9.43 \\
\hline $150 \mathrm{~h}$ & 254.00 & 187.00 & 250.50 & 17.00 & 72.66 & 45.34 & 67.29 & 6.75 \\
\hline
\end{tabular}

The kinetics of the number of cycles as a function of the exposure time, according to the hair sensitization level, is shown in Figure 2.

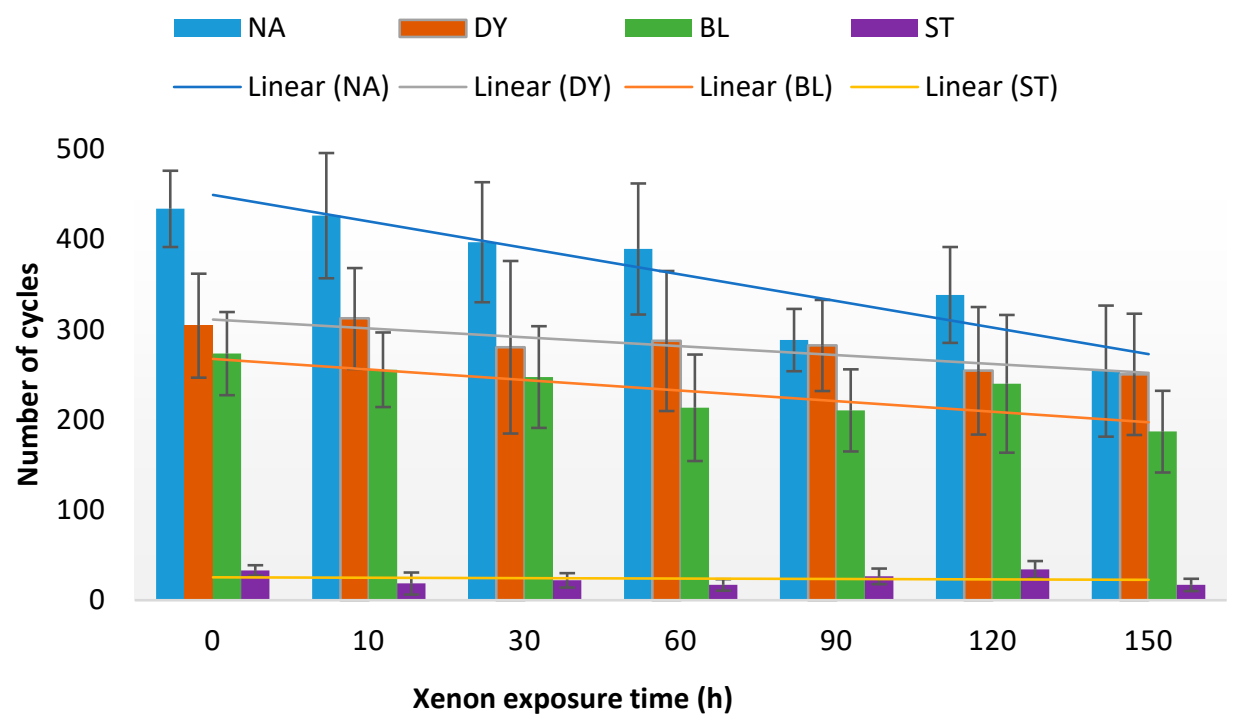

Figure 2. The number of flexabrasion cycles before the hair breakage occurs as a result of exposure time to the Xenon arc lamp for each group of sample sensitization levels (NA, BL, DY, and ST).

Before the irradiation exposure $(t=0 \mathrm{~h})$, the mechanical response to flexabrasion measurements reflected the control fiber condition represented by the natural group and the chemical treatment effects illustrated by the bleached, dyed and straightened sample groups. Figure 2 shows that in their initial condition, in which no radiation exposure was performed $(t=0 \mathrm{~h})$, NA strands required a significantly higher number of cycles to induce breakage when compared to the other groups, demonstrating the preserved mechanical properties of fibers that received no chemical intervention or radiation exposure, and contributing as a reference for hair-shaft mechanical property integrity. The decreased performance of chemically treated samples BL, DY, and ST, previous to any radiation exposure, show the mechanical impact stemming from these approaches, corroborating research in the literature indicating the decreased strength of chemically treated hair fibers $[8,26]$.

There is no significant difference between the BL and DY groups' degradation of mechanical properties before radiation exposure, as shown by the partial overlapping of their uncertainty bands, shown in Figure 2 for $t=0 \mathrm{~h}$. However, the ST group presented values of the number of cycles before breakage that were significantly inferior to the other groups, demonstrating the high impact of formaldehyde on the hair fiber's mechanical properties. The decreased mechanical properties of the bleached strands are caused by 
the degradation of the cystine molecules [8], which are the main amino acids that provide mechanical resistance in the fibers. This degradation results in the breakage of the disulfide bonds that link the intermediated filaments of the keratin, inducing a direct impact on the rigidity of the cortex assembly. Moreover, the bleaching process oxidizes melanin, the absence of which causes significant changes in the resistance of the hair shaft when compared to pigmented hair $[1,9]$.

During the coloring process, an alkaline lightening agent accompanies the fixation of colorants [10]. This process progressively changes the condition and physicochemical characteristics of the hair and, after multiple applications, the hair shaft tends to resemble bleached hair [10]. The results shown in Figure 2 for colored hair, demonstrating additional mechanical degradation when exposed to radiation, corroborates the study described in [7], in which dyed hair that was subjected to simulated sunlight irradiation led to a loss of tensile strength [7]. This study also demonstrated a significant decrease in the total elongation of colored hair fibers when subjected to specific radiation wavelengths [7]. With no radiation exposure, the literature indicates the removal of 18-methyleicosanoic acid of the outermost lipid layer and the oxidation of disulfide bonds in cysteine proteins, resulting from chemical dyeing processes $[1,27,28]$. These chemical effects explain the mechanical degradation that was already present in samples that underwent the dyeing pretreatment before being irradiated (time $=0 \mathrm{~h}$ ).

Formaldehyde, in turn, is known for stiffening the capillary fibers, due to the induced reticulation of the protein chains [29]. This property reduces the capability of the structures to slide over each other when mechanically stressed, enhancing the shaft's rigidity. This latter condition can lead to a higher stress concentration where the strand of hair is bent over the metallic wire, severely increasing its breakage propensity, as shown in the values for time $=0 \mathrm{~h}$ in Figure 2, when no radiation exposure was performed but only the chemical pretreatment procedure.

The method's sensitivity was analyzed by evaluating the results as a function of the radiation exposure time. For this assessment, the linear regression of data from the flexabrasion test for each group of different levels of capillary sensitization was obtained. The equations and the coefficient of determination $R^{2}$ for each studied group are shown in Figures $3-5$.

Natural hair(NA)

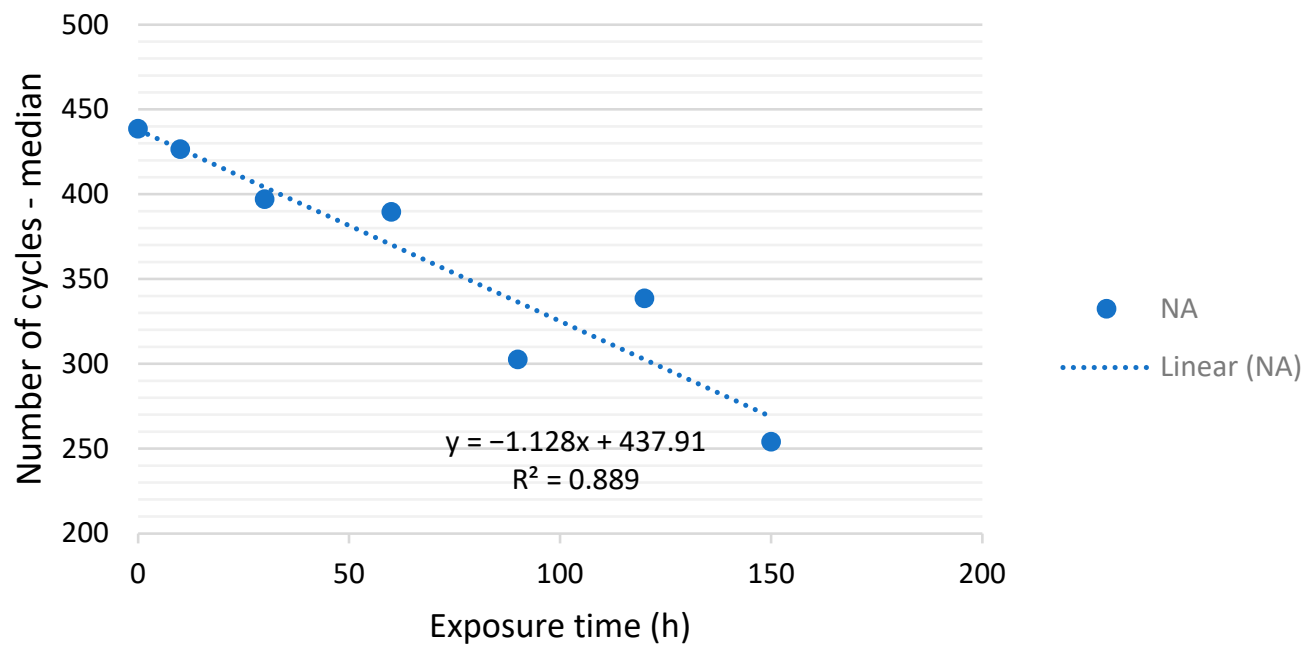

Figure 3. Linear regression of the data obtained for the natural hair group. 


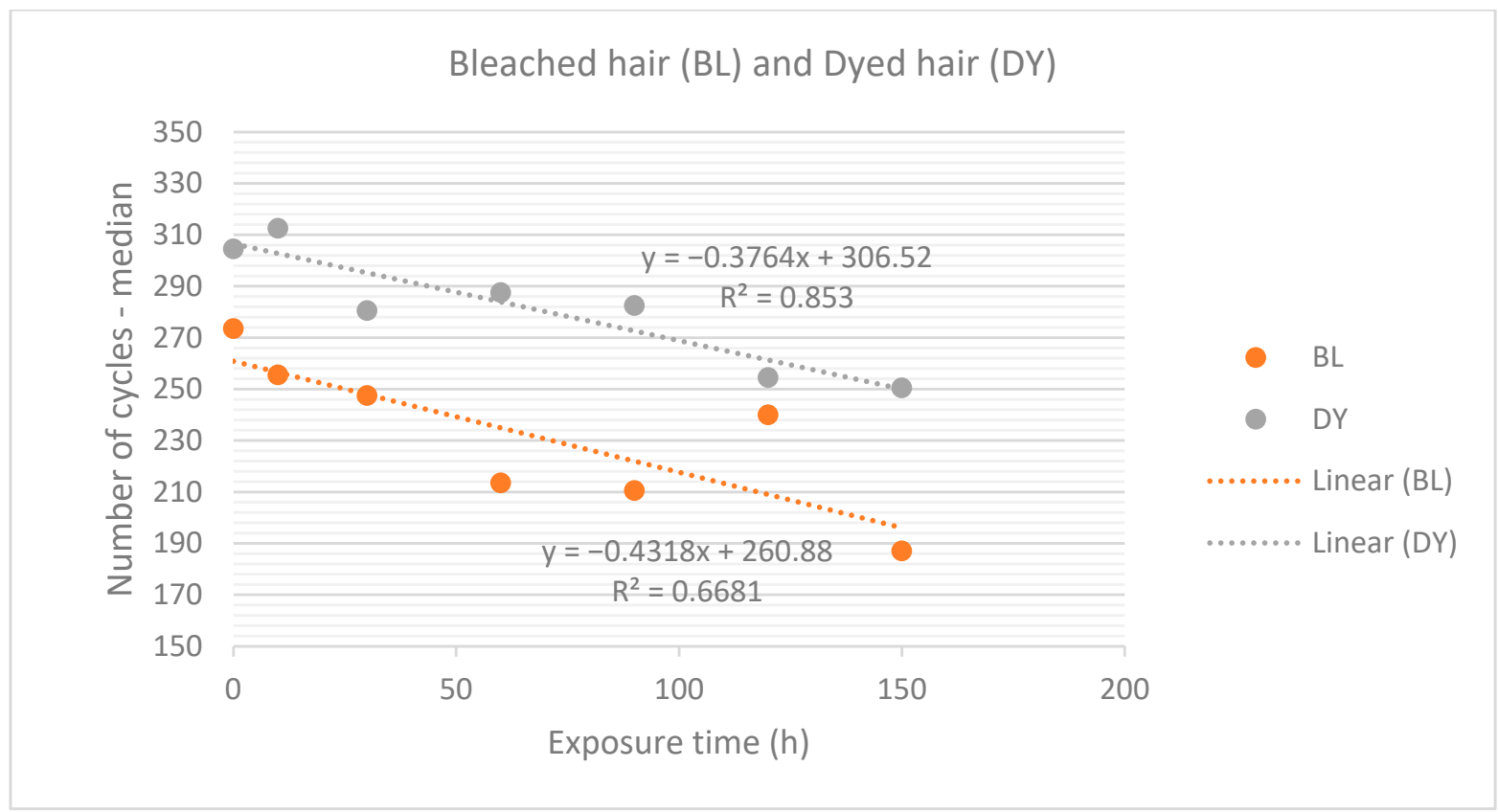

Figure 4. Linear regression of the data obtained for the bleached and dyed hair groups.

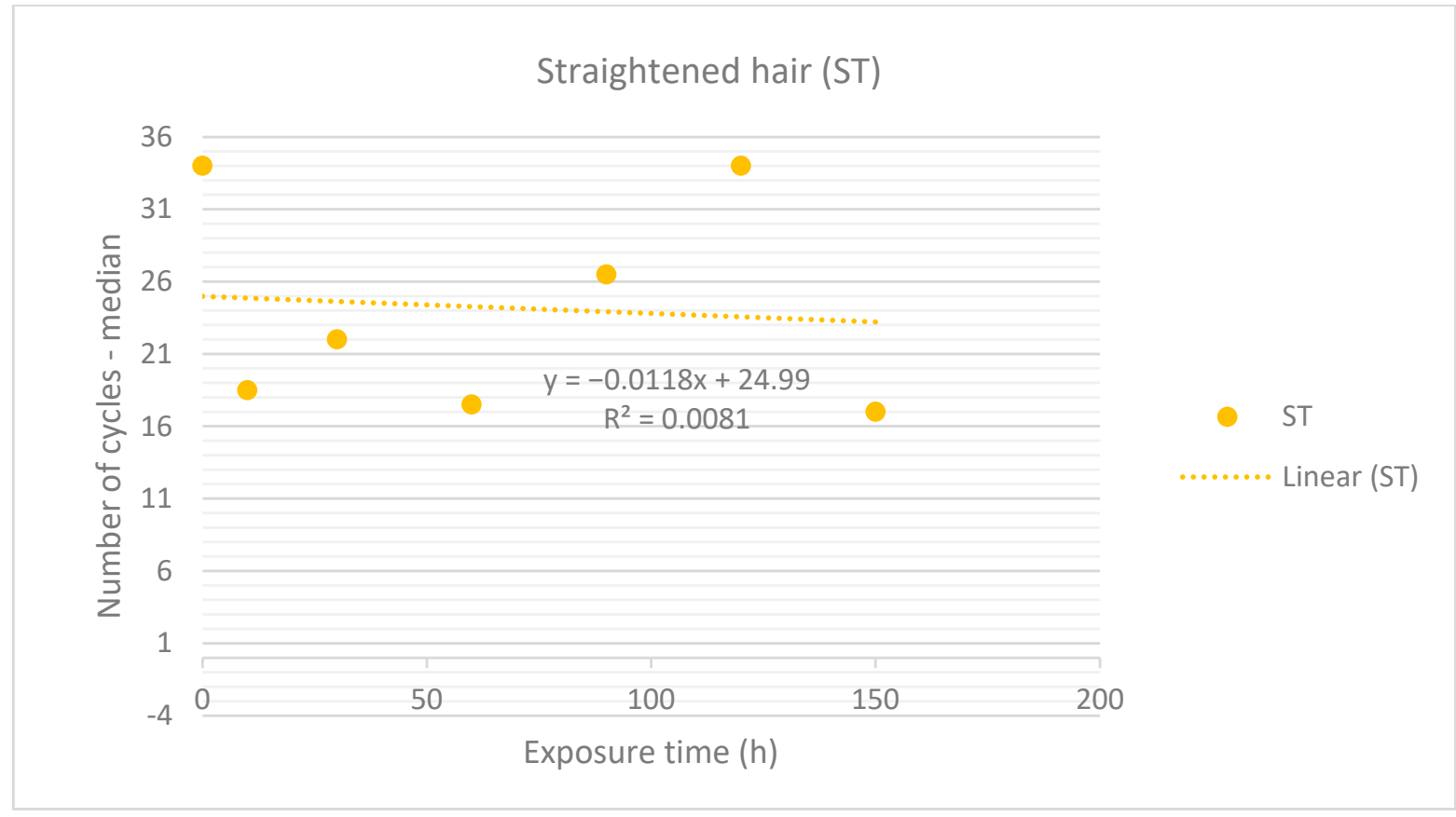

Figure 5. Linear regression of the data obtained for the straightened hair group.

In general, negative angular coefficients are observed, indicating the decay of cycles until the fiber ruptures with increasing radiation exposure time. Namely, the longer the hair is exposed to the sun, the lower is the mechanical resistance. However, the straightened hair group presents an angular coefficient of close to zero (Figure 5), characterizing an asymptotic behavior as a function of the radiation exposure time. Thus, it is assumed that hair treated with this type of chemical straightening does not appear to have its mechanical properties significantly altered by sun exposure. This result is probably due to the very low preservation of these properties of fibers that have undergone the formaldehyde application procedure before being exposed to solar radiation. 
The natural and dyed hair groups have a coefficient of determination closer to 1 , indicating better linearity of the strands' resistance with exposure time than the other two groups. The natural hair group shows the most expressive decay in the number of cycles before failure, depending on the exposure time (angular coefficient equal to -1.128). This result indicates that the group's mechanical properties respond with greater sensitivity to radiation stimulus than the other three groups studied.

Due to their initial conditions of greater hair structure integrity, the resistance decay associated with the natural hair group is more expressive than that of the other groups. At the first step, before the radiation stage, the natural group presented a "number of cycles before fiber breakage" of around 1.5 times higher than the dyed or bleached group and 13 times superior to that of straightened swatches.

The harmful effect of chemical treatments on fiber constituents overlaps the impact of solar radiation on the hair's mechanical properties. The results indicate that the higher the number of cycles before rupture at the starting phase of the study, the more significant is its decay as a function of exposure time.

It is noteworthy that after $90 \mathrm{~h}$ of exposure to the Xenon arc lamp, the number of cycles necessary for the breakage of natural hair shafts comes closer to the required number for the rupture of hair that has undergone the process of bleaching or dyeing (Figure 2).

The literature indicates that the damage expressed by an increase in the number of soluble proteins extracted from the hair shaft in an aqueous medium is produced both by bleaching reagents and UV radiation $[3,4,15,21-23,30,31]$. The partial overlapping of the uncertainty bands indicates that the results may be statistically compatible. An evident overlap is observed when comparing the uncertainty band of natural hair at a given exposure time $(90 \mathrm{~h})$ with those bands presented by bleached or dyed swatches before solar exposure (time $=0 \mathrm{~h}$ ). This result reveals that the photodamage suffered by natural hair strands after $90 \mathrm{~h}$ exposure is equivalent to the deterioration of hair strands subjected to chemical treatments such as BL or DY before being exposed to solar radiation $(t=0 \mathrm{~h})$.

The Mann-Whitney test was used with the aid of the XLSTAT 2018 program, for a significance level of 5\%, to compare the values obtained for each exposure time with the values obtained for samples not subjected to Ci3000 equipment treatment $(0 \mathrm{~h}$, i.e., without exposure). Table 4 shows the statistical comparisons obtained for each group analyzed: green cells with the symbol " $=$ " indicate that there is no statistically significant difference between the analyzed samples; that is, the $p$-value obtained is greater than 0.05 . On the other hand, red cells with the symbol " $\neq$ " indicate that there is a statistically significant difference between the samples analyzed; that is, the $p$-value obtained is less than 0.05 .

Table 4. Summary of Mann-Whitney statistical analysis comparing samples for each exposure time with samples not exposed to the Xenon arc lamp.

\begin{tabular}{|c|c|c|c|c|c|c|}
\hline \multicolumn{7}{|c|}{ Mann-Whitney Test-Comparison with $0 \mathrm{~h}$ of Exposure Time } \\
\hline Samples & $10 \mathrm{~h}$ & $30 \mathrm{~h}$ & $60 \mathrm{~h}$ & $90 \mathrm{~h}$ & $120 \mathrm{~h}$ & $150 \mathrm{~h}$ \\
\hline NA & $=$ & $=$ & $\neq$ & $\neq$ & $\neq$ & $\neq$ \\
\hline BL & $=$ & $=$ & $\neq$ & $=$ & $=$ & $\neq$ \\
\hline DY & $=$ & $=$ & $=$ & $=$ & $\neq$ & $\neq$ \\
\hline ST & $=$ & $\neq$ & $\neq$ & $=$ & $=$ & $\neq$ \\
\hline
\end{tabular}

The samples of natural hair (NA) and dyed hair (DY) show greater consistency in the results. For NA, the loss of mechanical resistance is noticeable after $60 \mathrm{~h}$ of exposure, while for DY, it is noticeable after $120 \mathrm{~h}$ of exposure. Although the effect of dyeing has already significantly impacted the fibers before sun exposure (Figure 2), possibly due to its damage being mainly associated with the deterioration of surface layers [1,27], some relevant mechanical properties were preserved before being irradiated, making it possible for the hair fibers to be more sensitive to the effects of radiation than the bleached fibers, which, in turn, undergo similar effects to those produced by UV radiation [3,4,15,21-23]. 
Therefore, for an exposure time $=0 \mathrm{~h}$, the prevailing damage to dyed hair may affect mainly the cuticle layers and, with radiation exposure, mechanical deterioration provided by damage to the cortical region is added, explaining the tensile response in [7] and the clear distinction between exposure times of $10 \mathrm{~h}$ and $120 \mathrm{~h}$.

\subsection{Estimate of the Equivalent Dose of Solar Radiation}

It was identified that, according to the flexabrasion method, natural hair begins to lose its mechanical properties after $60 \mathrm{~h}$ of exposure to the Xenon arc lamp. In order to understand how much of the everyday reality this can reflect, the correlation of this experimental exposure with the exposure to solar radiation was calculated.

Based on the 2015 climate data for the city of Rio de Janeiro, obtained from the weather company (Climatempo Assessoria e Consultoria Meteorologica LTDA. Vila Mariana, Sao Paulo, Brazil), the radiation dose received by people exposed to the sun's rays for $1.5 \mathrm{~h}$ per day was estimated. Rio de Janeiro is a metropolis of global dimensions, with significant beach tourism, especially during the summer season. According to the estimated data, $60 \mathrm{~h}$ of Xenon arc lamp exposure is equivalent, for example, to the actual dose received during the first five months of 2015, considering $1.5 \mathrm{~h}$ of daily exposure. Therefore, a person exposed to the sun for about $1.5 \mathrm{~h}$ per day may have their hair significantly damaged in 5 months.

If we consider the total exposure for January with the total insolation time recorded for this month in 2015 in Rio de Janeiro, the equivalence to Xenon arc lamp exposure under the conditions selected for this study would be $129.62 \mathrm{~h}$. The 60-h equivalent of Xenon arc lamp exposure for this summer month would be about 15 days. Consequently, a person exposed to the sun throughout an entire day at the peak of summer will have their hair significantly weakened after two weeks.

The dose equivalent of the radiation intensity from $60 \mathrm{~h}$ of exposure under the conditions selected for this study can be estimated as follows.

Considering a wavelength range of from $300 \mathrm{~nm}$ to $3000 \mathrm{~nm}$, the radiation intensity, $I_{X 300-3000}$, of the Xenon arc lamp for this range is:

$$
I_{X 300-3000}=R_{R J} \times I_{X 300-400}=1523.71 \mathrm{~W} \cdot \mathrm{m}^{-2}
$$

where $R_{R J}=25.40$ is the estimated relationship between the intensity of solar radiation from $300 \mathrm{~nm}$ to $3000 \mathrm{~nm}$ and the intensity of solar radiation from $300 \mathrm{~nm}$ to $400 \mathrm{~nm}$, according to ASTM G173-03 [23], considering an average between the values obtained for direct normal irradiance and hemispherical tilted irradiance; and $I_{X 300-400}=60 \mathrm{~W} \cdot \mathrm{m}^{-2}$ is the set radiation intensity emitted by the Xenon arc lamp for the wavelength range from $300 \mathrm{~nm}$ to $400 \mathrm{~nm}$.

Therefore, the radiation dose, $D_{\mathrm{X} 300-3000}$, can be calculated as:

$$
D_{X 300-3000}=t_{X} \times I_{X 300-3000}=329.12 \mathrm{MJ} \cdot \mathrm{m}^{-2}
$$

where $t_{X}=60 \mathrm{~h}$ is the selected time of exposure to the Xenon arc lamp.

Thus, to simulate the same $60 \mathrm{~h}$ of exposure of this study in different exposure systems, a radiation dose of $329.12 \mathrm{MJ} \cdot \mathrm{m}^{-2}$ for the range from $300 \mathrm{~nm}$ to $3000 \mathrm{~nm}$ of the spectrum of solar radiation should be ensured.

\section{Conclusions}

In order to ensure the effectiveness of products that claim to offer hair photoprotection, there must be a methodology capable of detecting variations in fiber integrity due to sun exposure. The present work evaluates the potential of the flexabrasion approach in determining the effect of solar radiation on the mechanical properties of hair strands, considering realistic exposure conditions.

The climatic conditions of Rio de Janeiro were selected for correlation with the parameters of an in vitro exposure of hair samples of different levels of sensitization with the aid 
of a Xenon arc lamp. The city was selected due to its high irradiation values, population, and global interest as a touristic area.

The flexabrasion test method results showed that, in general, the number of cycles for the breakage of hair fibers presents a non-normal distribution. Thus, the nonparametric statistical Mann-Whitney test was used to compare the different groups of samples.

The resistance of the strands, determined by the number of abrasion cycles related to their breakage point, was inversely proportional to the exposure time to Xenon arc lamp radiation for natural, bleached, and dyed hair swatches. The results indicated that the higher the initial integrity of the fiber to be analyzed, the greater the decay dynamics of the number of cycles as a function of exposure time.

The hair samples subjected to a $10 \%$ formaldehyde solution presented the mechanical properties of hair strands that had already considerably decayed before radiation exposure. The number of cycles for breakage was significantly reduced by $90 \%$, compared to natural hair. For this group of samples, there was no relationship between the experimental exposure time and the mechanical resistance of the hair shaft, indicating that the damage caused by formaldehyde overlapped the damage caused by solar radiation.

The impact of different radiation doses on hair fiber properties was more clearly evidenced in the natural hair strands. It was possible to identify a significant reduction in their mechanical resistance after $60 \mathrm{~h}$ of exposure. In practical terms, this means that the natural hair of a person who exposes themselves to the sun in Rio de Janeiro for about $1.5 \mathrm{~h}$ per day has significantly reduced mechanical properties after about five months of a usual routine.

Based on the studies performed in the present work, the following standardization of variables can be proposed to harmonize the preparation of hair samples and sun exposure simulation, which can be applied for the assessment of solar protection hair products:

- Use of brown coloration natural strands;

- Total radiation dose of $329.12 \mathrm{MJ} \cdot \mathrm{m}^{-2}$ for the wavelength range of $300 \mathrm{~nm}$ to $3000 \mathrm{~nm}$ of the solar spectrum, or the equivalent for the assessment of different wavelength windows;

- $\quad$ Temperature of $40^{\circ} \mathrm{C}$;

- Relative humidity of $50 \%$.

The results showed the ability of the flexabrasion technique to detect the effect of photodamage on the mechanical properties of human hair strands. This technique has been shown to be more effective than the conventional approach employing the tensile test method since flexabrasion also considers the weakening of the cuticular region, which is more impacted by radiation than is the cortical area.

Therefore, the proposed methodology of sample irradiation and flexabrasion measurements is indicated for the evaluation of the harmful effects of solar radiation on human hair fibers, with potential application in appraising the efficacy of products intended for hair photoprotection; thus, enabling a proper assessment of their compliance with national regulatory requirements.

Author Contributions: Conceptualization, N.F.d.O., R.R., A.G., D.G.M. and E.C.M.; methodology, N.F.d.O., R.R., A.G., E.C.d.O. and E.C.M.; validation, N.F.d.O., A.G., D.G.M., E.C.d.O. and E.C.M.; formal analysis, N.F.d.O., A.G., E.C.d.O. and E.C.M.; investigation, N.F.d.O., A.G., E.C.d.O. and E.C.M.; resources, N.F.d.O., R.R., A.G., D.G.M.; data curation, N.F.d.O., R.R.; writing-original draft preparation, N.F.d.O., E.C.d.O. and E.C.M.; writing-review and editing, A.G., D.G.M., E.C.d.O. and E.C.M.; visualization, N.F.d.O. and E.C.M.; supervision, N.F.d.O., A.G., D.G.M. and E.C.M.; project administration, N.F.d.O., A.G. and D.G.M.; funding acquisition, N.F.d.O., A.G. and D.G.M. All authors have read and agreed to the published version of the manuscript.

Funding: The authors thank for the financial support provided by the Brazilian funding agency CAPES (Coordenação de Aperfeiçoamento de Pessoal de Nível Superior-Brazil-Finance Code 001).

Institutional Review Board Statement: Not applicable. 
Informed Consent Statement: Not applicable.

Acknowledgments: The authors thank L'Oréal for all the support provided, making the study's measurements carried out possible.

Conflicts of Interest: Elisabeth Costa Monteiro-professor at the Pontifical Catholic University of Rio de Janeiro, Rio de Janeiro, Brazil. Nathália F. de Oliveira and Daiane Garcia Mercurio-L'Oréal Research \& Innovation, Rio de Janeiro, Brazil; Elcio Cruz de Oliveira-Technology Management, Petrobras Transporte S.A., Rio de Janeiro, Brazil and Pontifical Catholic University of Rio de Janeiro, Rio de Janeiro, Brazil; Rima Rakshit—L'Oréal Research \& Innovation, Mumbai, India; Anthony Galliano-L'Oréal Research \& Innovation, Saint Ouen, France. The authors declare no conflict of interest associated with the developed research theme, which proposes a method for harmonized evaluation of photoprotection efficacy of hair-care products.

\section{References}

1. Dario, M.F.; Baby, A.R.; Velasco, M.V.R. Effects of solar radiation on hair and photoprotection. J. Photochem. Photobiol. B Biol. 2015, 153, 240-246. [CrossRef] [PubMed]

2. Gao, T.; Bedell, A. Ultraviolet damage on natural gray hair and its photoprotection. J. Cosmet. Sci. 2001, 52, 103-118. [PubMed]

3. Nogueira, A.C.S.; Joekes, I. Hair color changes and protein damage caused by ultraviolet radiation. J. Photochem. Photobiol. B Biol. 2004, 74, 109-117. [CrossRef] [PubMed]

4. Tanji, N.; Inoue, S.; Okamoto, M.; Tokunaga, S.; Tanamachi, H. ToF-SIMS characterization of the lipid layer on the hair surface. I: The damage caused by chemical treatments and UV radiation. Surf. Interface Anal. 2011, 43, 410-412. Available online: https:/ / analyticalsciencejournals.onlinelibrary.wiley.co (accessed on 4 November 2021).

5. Richena, M.; Rezende, C.A. Effect of photodamage on the outermost cuticle layer of human hair. J. Photochem. Photobiol. B Biol. 2015, 153, 296-304. [CrossRef] [PubMed]

6. Nogueira, A.C.S.; Dicelio, I.; Joekes, I. About photo-damage of human hair. Photochem. Photobiol. Sci. 2006, 5, 165-169. [CrossRef]

7. Hoting, E.; Zimmermann, M. Sunlight-induced modifications in bleached, permed, or dyed human hair. J. Soc. Cosmet. Chem. 1997, 48, 79-91.

8. Robbins, C. Chemical and Physical Behavior of Human Hair, 5th ed.; Springer: New York, NY, USA, 2012.

9. Lee, W.S. Hair Photoaging. In Aging Hair; Trüeb, R., Tobin, D., Eds.; Springer: Berlin/Heidelberg, Germany, $2010 ;$ pp. 123-133.

10. Bouillon, C.; Wilkinson, J.C. The Science of Hair Care, 2nd ed.; Taylor \& Francis Group: Boca Raton, FL, USA, 2005.

11. Swift, J.A.; Chahal, S.P.; Coulson, D.L.; Challoner, N.I. Flexabrasion: A Method for Evaluating Hair Strength. Cosmet. Toilet. Sci. Appl. 2014, 129, 5. Available online: https://www.cosmeticsandtoiletries.com/testing/methoddevelopment/From-the-Archives-Flexabrasion-A-Method-for-Evaluating-Hair-Strengthpremium-259971381.html (accessed on 12 March 2020).

12. da Gama, R.M.; Baby, A.R.; Velasco, M.V.R. In Vitro Methodologies to Evaluate the Effects of Hair Care Products on Hair Fiber. Cosmetics 2017, 4, 2. [CrossRef]

13. Kuzuhara, A. Analysis of internal structure changes in black human hair keratin fibers resulting from bleaching treatments using Raman spectroscopy. J. Mol. Struct. 2013, 1047, 186-193. [CrossRef]

14. Cloete, E.; Khumalo, N.P.; Ngoepe, M.N. The what, why and how of curly hair: A review. Proc. R. Soc. A 2019, 475, 0516 [CrossRef]

15. Fedorkova, M.V.; Brandt, N.N.; Chikishev, A.Y.; Smolina, N.V.; Balabushevich, N.G.; Gusev, S.A.; Lipatova, V.A.; Botchey, V.M.; Dobretsov, G.E.; Mikhalchik, E.V. Photoinduced formation of thiols in human hair. J. Photochem. Photobiol. B Biol. 2016, 164, 43-48. [CrossRef]

16. Maeda, K.; Yamazaki, J.; Okita, N.; Shimotori, M.; Igarashi, K.; Sano, T. Mechanism of Cuticle Hole Development in Human Hair Due to UV-Radiation Exposure. Cosmetics 2018, 5, 24. [CrossRef]

17. Morton, W.E.; Hearle, J.W.S. Physical Properties of Textile Fibres, 4th ed.; Woodhead Publishing limited: Cambridge, UK, 2008.

18. Leroy, F.; Franbourg, A.; Grognet, J.C.; Vayssie, C.; Bauer, D. Flexabrasion: A new test for predicting human hair resistance. In Proceedings of the First Tricontinental Meeting on Hair Research Society, Brussels, Belgium, 8-10 October 1995.

19. Bertrand, L.; Doucet, J.; Simionovici, A.; Tsoucaris, G.; Walter, P. Lead-revealed lipid organization in human hair. Biochim. Biophys. Acta 2003, 1620, 218-224. [CrossRef]

20. Swift, J.A.; Coulson, D.; al Bayatti, M.F. The intra-fibre flexabrasion test. A powerful method in the evaluation of hair toiletry products. In Proceedings of The 10th International Wool Textile Research Conference, Aachen, Germany, 26 November-1 December 2000

21. de la Mettrie, R.; Saint-Léger, D.; Loussouarn, G.; Garcel, A.; Porter, C.; Langaney, A. Shape variability and classification of human hair: A worldwide approach. Hum. Biol. 2007, 79, 265-281. [CrossRef]

22. Atlas Material Testing Technology. Ci3000+/Ci4000/Ci5000 Weather-Ometer ${ }^{\circledR}$ : General Equipment Specifications Manual Ci3000 Atlas; 2014.

23. ASTM G173-03:2012; Standard Tables for Reference Solar Spectral Irradiance: Direct Normal and Hemisferical on $37^{\circ}$ Tilted Surface; ASTM International: West Conshohocken, PA, USA, 2012. [CrossRef] 
24. Campos, C.V.C.; de Oliveira, E.C.; Barbosa, C.R.H. Methodology for evaluation of methods for volume correction of liquid oil derivatives. Measurement 2020, 153, 107388. [CrossRef]

25. de Holleben, C.; de Oliveira, E.C. Variations in the classification of laboratory performance due to different protocols for use in proficiency testing programs. Measurement 2020, 152, 107354. [CrossRef]

26. Bloch, L.D.; Goshiyama, A.M.; Dario, M.F.; Escudeiro, C.C.; Sarruf, F.D.; Velasco, M.V.R.; Valente, N.Y.S. Chemical and physical treatments damage Caucasian and Afro-ethnic hair fibre: Analytical and image assays. J. Eur. Acad. Dermatol. Venereol. 2019, 33, 2158-2167. [CrossRef]

27. Brown, M.A.; Hutchins, T.A.; Gamsky, C.J.; Wagner, M.S.; Page, S.H.; Marsh, J.M. Liquid crystal colloidal structures for increased silicone deposition efficiency on colour-treated hair. Int. J. Cosmet. Sci. 2010, 32, 193-203. [CrossRef]

28. Robbins, C.; Weigmann, H.-D.; Ruetsch, S.; Kamath, Y. Failure of intercellular adhesion in hair fibers with regard to hair condition and strain conditions. J. Cosmet. Sci. 2004, 55, 351-371. [CrossRef]

29. Mcmullen, R.L.; Gillece, T.; Laura, D.; Zhang, G.; Thompson, W.; Wossene, S. Investigation of Physicochemical Changes in Hair as a Result of Treatment with Formaldehyde and Thermal Styling Devices. In Proceedings of the TRI's International Conference on Applied Hair Science, Princeton, NJ, USA, 18-19 September 2014.

30. Fernandez, E.; Barba, C.; Alonso, C.; Marti, M.; Parra, J.L.; Coderch, L. Photodamage determination of human hair. J. Photochem. Photobiol. B 2012, 106, 101-106. [CrossRef]

31. Sandhu, S.S.; Robbins, C.R. A simple and sensitive technique, based on protein loss measurements, to assess surface damage to human hair. J. Soc. Cosmet. Chem. 1993, 44, 163-175. 